\title{
Experimental investigation of blades number of savonius water turbine on performance characteristic
}

Cite as: AIP Conference Proceedings 2217, 030165 (2020); https://doi.org/10.1063/5.0001063

Published Online: 14 April 2020

Dwiseno Wihadi, and Stefan Mardikus

ARTICLES YOU MAY BE INTERESTED IN

Factorial design of the effect of reaction temperature and reaction time on biodiesel production

AIP Conference Proceedings 2217, 030052 (2020); https://doi.org/10.1063/5.0000505

Numerical solution of Darcy-Brinkman-Forchheimer equation for forced-convective fluid flow through porous medium using DMLPG method

AIP Conference Proceedings 2217, 030171 (2020); https://doi.org/10.1063/5.0000586

Characterization and bioactivity test of secondary metabolite isolated from ethyl acetic fraction of Petrosia alfiani sponge from Barrang Lompo Island

AIP Conference Proceedings 2217, 030164 (2020); https://doi.org/10.1063/5.0000909
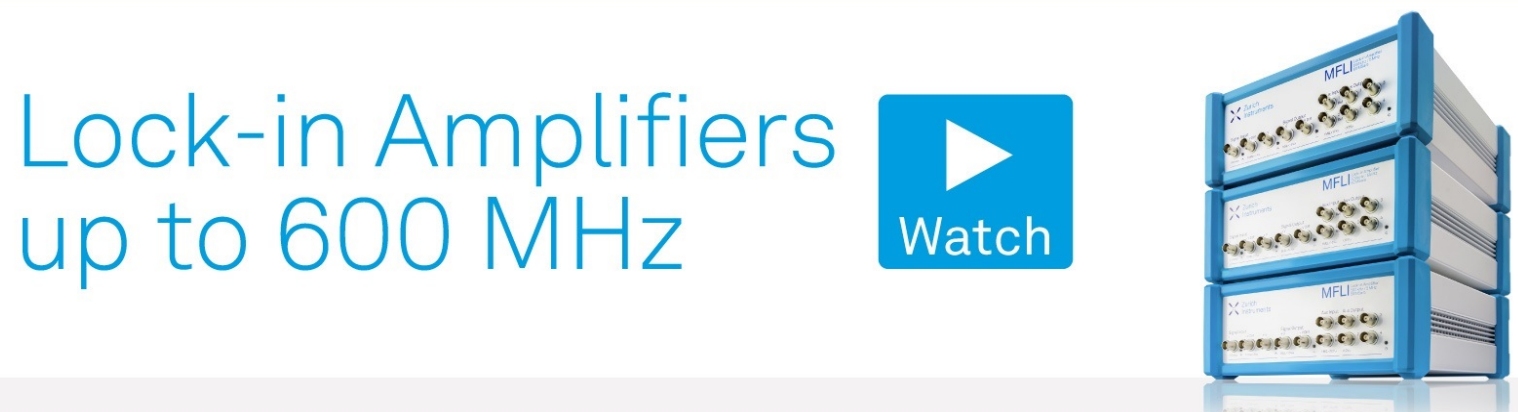


\title{
Experimental Investigation of Blades Number of Savonius Water Turbine on Performance Characteristic
}

\author{
Dwiseno Wihadi ${ }^{1, a)}$ and Stefan Mardikus ${ }^{1, b)}$ \\ ${ }^{1}$ Sanata Dharma University, Yogyakarta, Indonesia \\ a)Corresponding author: wihadi@usd.ac.id \\ ${ }^{b}$ stefan@usd.ac.id
}

\begin{abstract}
The use of water energy in irrigation channels has not been widely carried out. Water and air are very important types of fluid. Beside main support of human life, water is energy producer which has long. Water energy conversion in channels does not cause substantial losses, problem of sound, space optimization. This experimental investigate the effect of blades number in Savonius water turbine to show the performance of turbine. Turbine is conducted with 2, 3, and 4 blades with 8 meters of water channel. The result showed that blades number of 2 can more improve than 3 or 4 of blades number the performance of water turbine which are represented by power coefficient and tip speed ratio.
\end{abstract}

\section{INTRODUCTION}

The use of water energy in irrigation channels has not been widely carried out. Water and air are very important types of fluid. Beside main support of human life, water is energy producer which has long. Water energy conversion in channels does not cause substantial losses, problem of sound, space optimization. Although any challenges in water stream with volumetric rate and waste water, Water stream in primary and secondary irrigation channels is relatively constant in volumetric rate and its direction that has relatively low velocity[1]. Research has been conducted to evaluate the effect of the number of blades on the Savonius wind turbine. Mahmoud et al in his research entitled "An experimental study on improvement of Savonius rotor performance" analyzed Savonius wind turbine with 2, 3 and 4 blades[2]. Mahmoud et al. concluded that the two-blade mill has better efficiency. Gupta R. and Biswas A. also concluded that the same as the H-Darrieus wind turbine in his research entitled "Comparative study of the performances of twisted two-bladed and three-bladed airfoils in the form of H-Darrieus turbines by computational and experimental methods"[3]. Evaluation of the effect of the number of blades on the water turbine was carried out by Hamzah I. et al. with the Savonius mill with a blade of 2, 4, 6, 8, 10, and 12 blades. The study was carried out in a computerized method using SolidWorks Computational Fluid Design (CFD) 2013. The study produced the conclusions of Savonius turbine with two blades having the best performance[4]. Through experimental tests the authors analyzed the performance of 2, 3 and 4 bladed water turbine in closed water passages. The mean velocity of flow in the aisle is set at a value of $0.8 \mathrm{~m} / \mathrm{s}, 0.9 \mathrm{~m} / \mathrm{s}$, and $1 \mathrm{~m} / \mathrm{s}$. The performance of the mill is represented by the power coefficient $(\mathrm{Cp})$, torque coefficient $(\mathrm{Cm})$, and tips speed ratio (tsr). 


\section{EXPERIMENTAL PROCEDURE}

This experiment was carried out with 3 turbines with 2, 3 and 4 blades, with the following specifications.

TABLE 1. Specifications of the Savonius Turbine.

\begin{tabular}{cccccccc}
\hline & Diameter (m) & & $\begin{array}{c}\text { Rotor Height (m) } \\
(\mathbf{H})\end{array}$ & Gap Distance & $\begin{array}{c}\text { Aspect Ratio } \\
(\boldsymbol{\alpha})\end{array}$ & $\begin{array}{c}\text { Overlap } \\
\text { Ratio }(\boldsymbol{\beta})\end{array}$ \\
\hline Plate (Df) & Rotor (D) & Blade (d) & & $(\mathbf{e}) \mathbf{~ m}$ & $\left(\mathbf{e}^{\prime}\right) \mathbf{~} \mathbf{m}$ & & \\
\hline 0.11 & 0.10 & 0.054 & 0.10 & 0.00811 & 0 & 1 & 0.15 \\
\hline
\end{tabular}

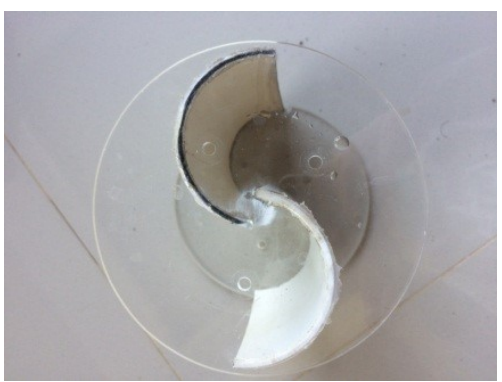

(a)

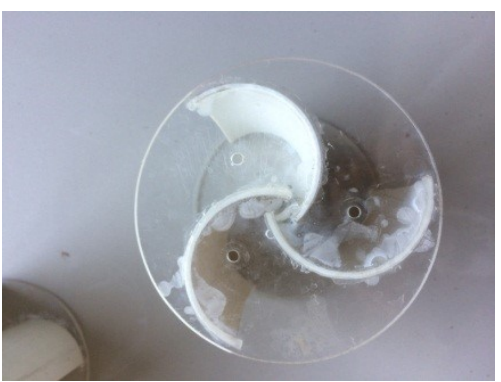

(b)

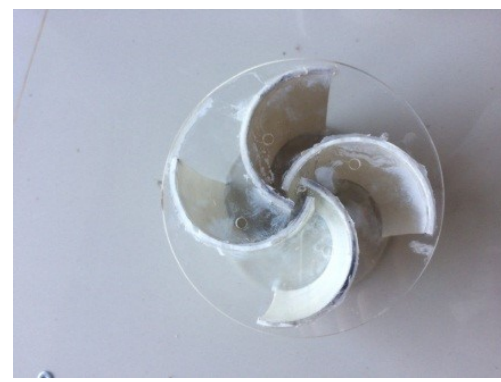

(c)

FIGURE 1. Model of the Savonius turbines (a) 2 blades, (b) 3 blades, and (c) 4 blades

The three turbines were installed in a closed 8 meters water channel with an effective cross section of $0.2 \times 0.2 \mathrm{~m}^{2}$. The maximum water flow rate that can be provided is $1.1 \mathrm{~m} / \mathrm{s}$. The flow rate is measured using the flow meter Swoffer 2100 which is placed in front of the turbines. The torque generated by the turbine is measured by a friction-based mechanism equipped with a digital style gauge. The equipment is assembled as shown in Figure 2 below, with (1) arm-brake shaft; (2) brake discs; (3) Brake lining; (4) Spring regulating brake pads; (5) connecting straps; (6) digital style gauges; (7) Arm-brakes; (8) Location of the turbine shaft rotational speed measurement; (9) turbine shaft end. The rotating speed of the wheel shaft is measured using a HT-4200 tachometer. The entire experimental equipment is assembled according to the design scheme shown in the following figure.
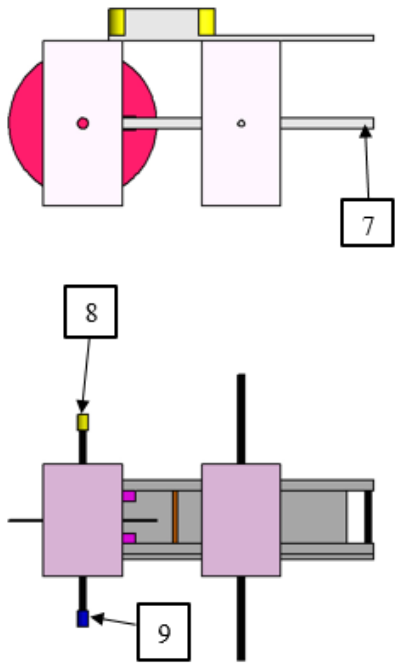
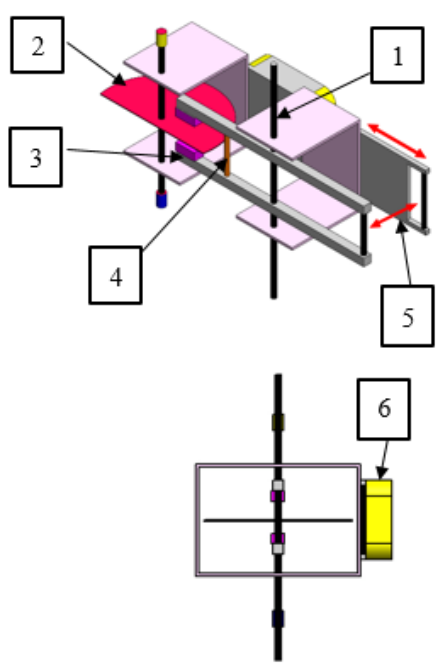

FIGURE 2. Torque measuring mechanism 


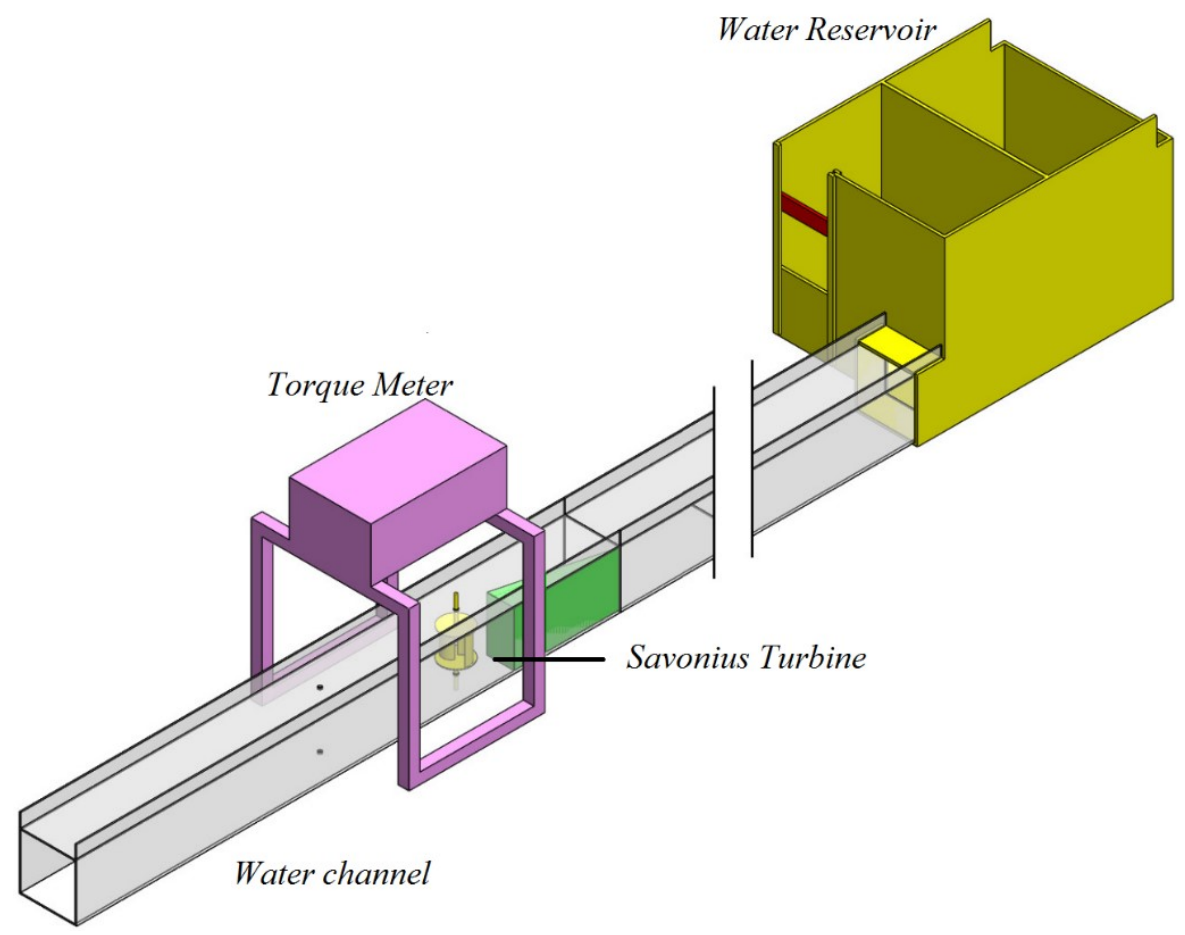

FIGURE 3. Schematic of the experimental circuit

RESULT AND DISCCUSSION

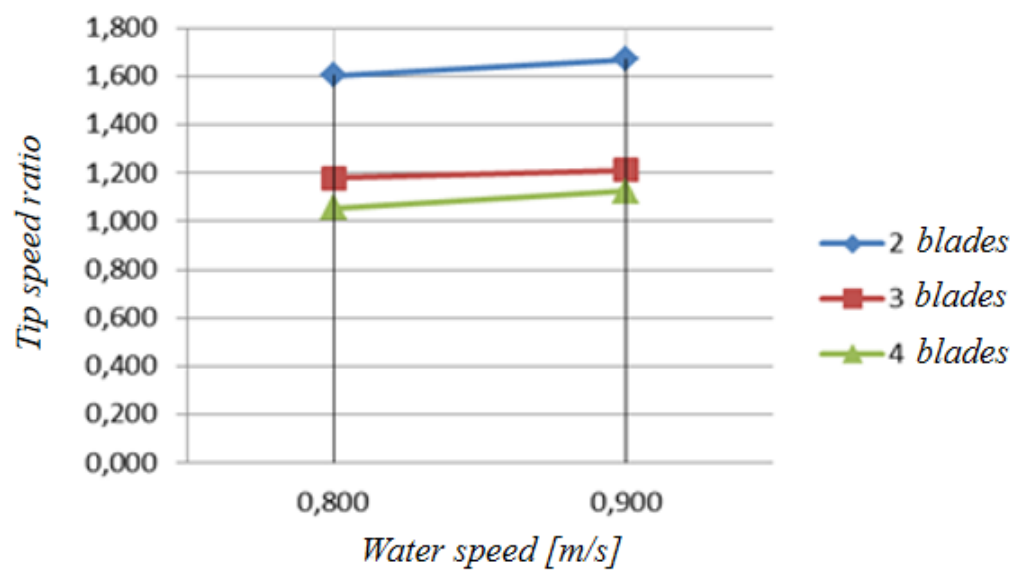

FIGURE 4. Correlation of velocity to tip speed ratio

In Fig. 4 showed that Savonius turbine of 2 blades had highest tip speed ratio of another blades. Although they had different in tip speed ratio gradient for 3 kinds of blades, but tip speed ratio increased because augment of water flow velocity for all model of blades with the same of swept area. When use of obstacle, coefficient of performance and tip speed ratio had different value for this parameters. In Fig. 5 if compared with two others model, the Savonius turbine of 2 blades had highest coefficient of performance. This case was corresponding with Fig. 5 and Fig. 6 of without flow director that the highest of coefficient of performance was $0.37[5]$. 


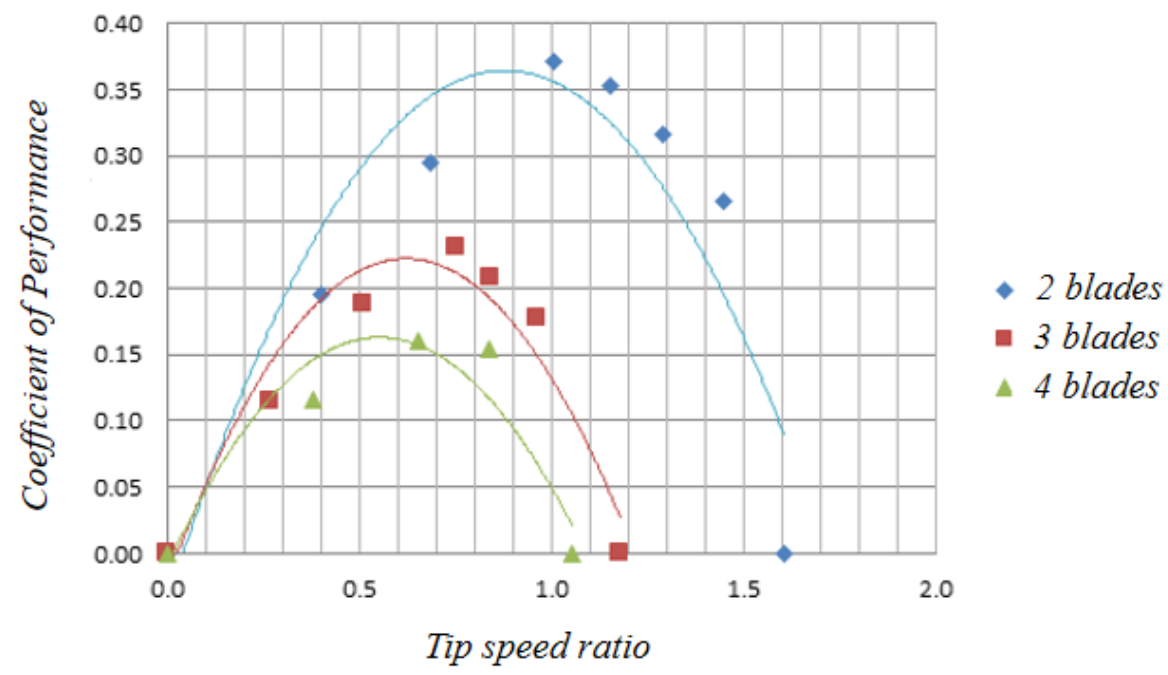

FIGURE 5. Between correlation of tip speed ratio and coefficient of performance on flow velocity of $0.8 \mathrm{~m} / \mathrm{s}$ without flow director.

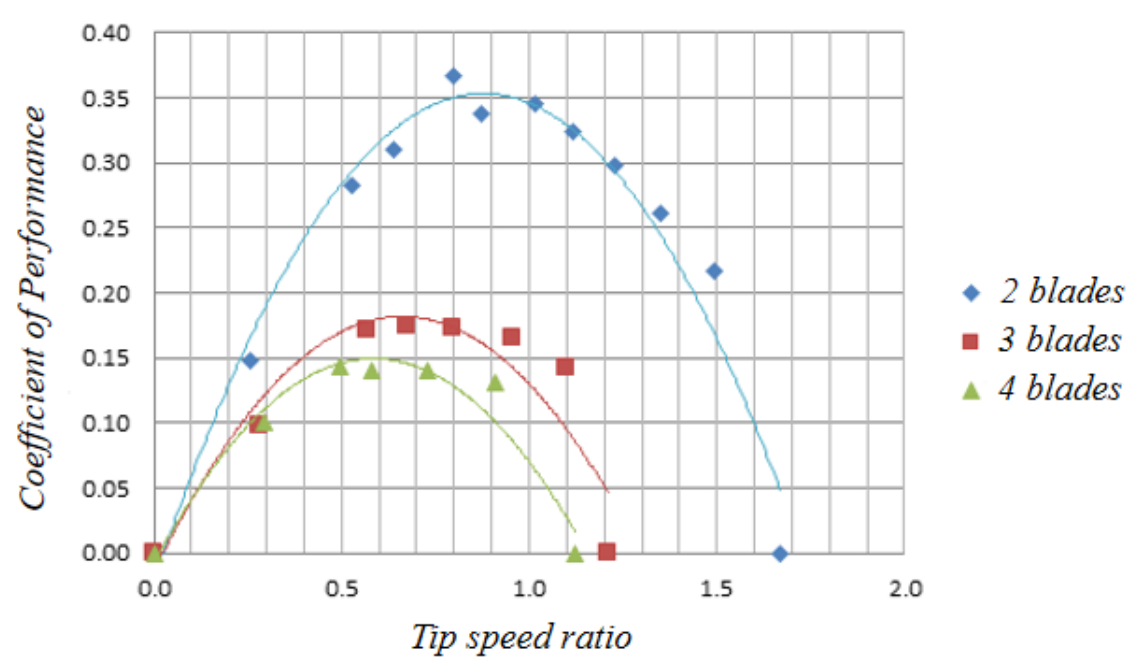

FIGURE 6. Between correlation of tip speed ratio and coefficient of performance on flow velocity of $0.9 \mathrm{~m} / \mathrm{s}$ without flow director.

The performance of Savonius turbine with flow director can be seen on Fig. 7 and Fig.8. when use of flow director, coefficient of performance increased because the flow director in the water channel augmented power extraction. Performance of 3 blades turbine was seen getting closer the performance of 2 blades turbine[6][7]. 


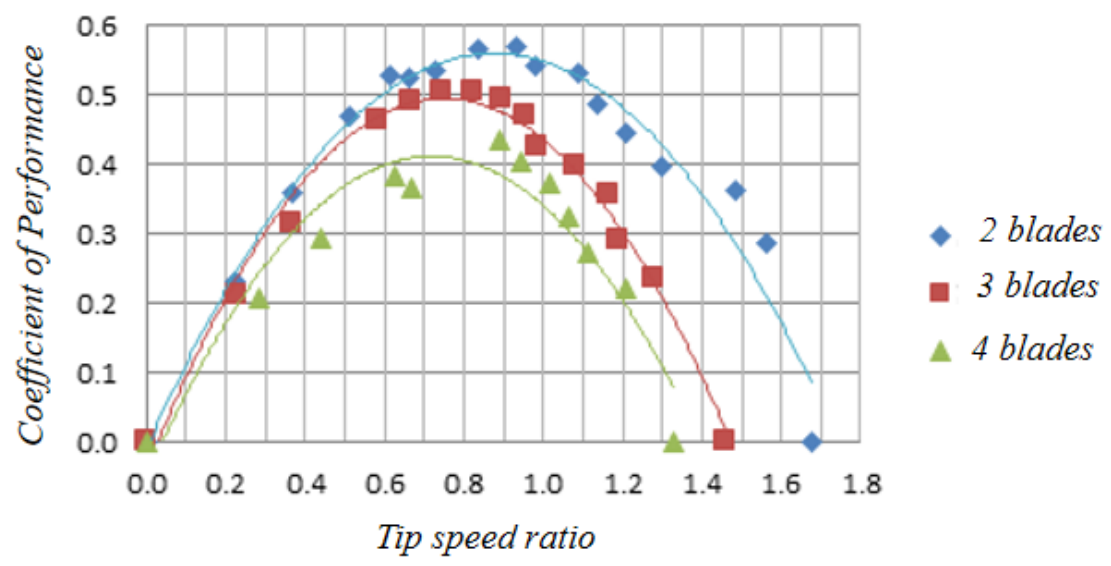

FIGURE 7. Between correlation of tip speed ratio and coefficient of performance on flow velocity of $0.8 \mathrm{~m} / \mathrm{s}$ with flow director.

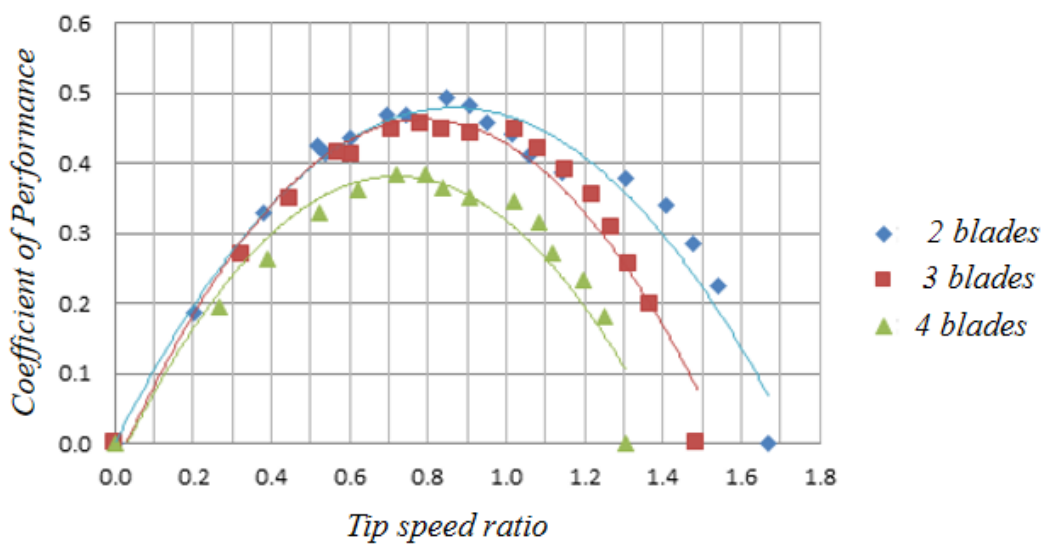

FIGURE 8. Between correlation of tip speed ratio and coefficient of performance on flow velocity of $0.9 \mathrm{~m} / \mathrm{s}$ with flow director.

\section{CONCLUSION}

The conclusion of this study showed that the effect of blades number different affected tip speed ratio and coefficient of performance. Based on this experimental, two blades of Savonius turbine had more powerful than three blades and four blades. The use of flow director can increase all variant of blade number.

\section{REFERENCES}

1. P. Sritram and R. Suntivarakorn, Energy Procedia, vol. 138, pp. 646-650, 2017.

2. N. H. Mahmoud, A. A. El-Haroun, E. Wahba, and M. H. Nasef, Alexandria Eng. J., vol. 51, no. 1, pp. 19$25,2012$.

3. A. R. Sengupta, A. Biswas, and R. Gupta, Renew. Energy, vol. 139, pp. 1412-1427, 2019.

4. I. Hamzah, A. Prasetyo, D. D. D. P. Tjahjana, and S. Hadi, AIP Conf. Proc., vol. 1931, no. February, pp. 1$6,2018$.

5. F. Behrouzi, M. Nakisa, A. Maimun, Y. M. Ahmed, and A. Salem Souf-Aljen, Energy Convers. Manag., vol. 181, no. July 2018, pp. 178-188, 2019.

6. S. Mauro, S. Brusca, R. Lanzafame, and M. Messina, Renew. Energy, vol. 141, pp. 28-39, 2019.

7. D. Jiyun, S. Zhicheng, and Y. Hongxing, Energy Procedia, vol. 145, pp. 363-367, 2018. 